\title{
ESTUDO DE MATERIAIS ALTERNATIVOS PARA A PRODUÇÃO DE CONCRETO DE CIMENTO PORTLAND
}

\author{
SANTOS, CRISTIANE CARINE DOS

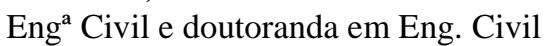 \\ Universidade Federal do Rio Grande do Sul \\ Rio Grande do Sul; Brasil \\ cristianecdossantos@hotmail.com \\ MUNARETTO COPETTI, MARINA \\ Engenheira Civil \\ Universidade Federal de Santa Maria \\ Rio Grande do Sul; Brasil \\ marinamunaretto@hotmail.com
}

\author{
DAL MOLIN, DENISE CARPENA COITINHO \\ Professora de ensino superior \\ Universidade Federal do Rio Grande do Sul \\ Rio Grande do Sul; Brasil \\ dmolin@ufrgs.br
}

\author{
MARTINS LEITE, LUCAS \\ Engenheiro Civil \\ PINHO VIEIRA, ANA EDUARDA \\ Acadêmica \\ Universidade Catótica de Brasília Universidade de Brasília \\ Brasília; Brasil \\ lukasm12007@gmail.com
}

\section{RESUMO}

O presente trabalho buscou analisar e comparar o potencial do uso da cinza de casca de arroz (CCA) e da sílica de casca de arroz (SCA) em misturas separadas, como material de substituição parcial do cimento e também a redução do mesmo em diferentes traços de concreto. Para tanto, produziu-se um traço referência, e a partir dele realizaram-se as substituições e reduções parciais de cimento em diferentes teores. As análises permitiram identificar qual das duas pozolanas estudadas apresentou o melhor desempenho quanto a resistência à compressão axial, absorção de água, índice de vazios, massa específica e abatimento do concreto. O estudo mostrou que quanto maior for o índice de substituição de cimento por alguma das pozolanas maior será a consistência adquirida pelo concreto, perdendo a fluidez. As misturas apresentaram-se com pouca diferença entre si quanto ao índice de vazios, massa especifica e absorção de água. A mistura que atingiu a maior resistência à compressão axial foi o S2 (10\% de SCA), aos 91 dias de idade, com 25,23\% de resistência a mais que o concreto referência. Porém, a mistura S6 (10\% de SCA+10\% de redução) foi a que mais conseguiu-se substituir e reduzir a quantidade de cimento mantendo assim praticamente as mesmas características que o traço referência. O estudo mostra que os traços com SCA tiveram resultados superiores aos traços com CCA, também, que é viável a substituição parcial do cimento por qualquer um dos dois tipos de pozolanas estudadas, aumentando a resistência a compressão axial do concreto, conseguindo benefícios técnicos e economia financeira, uma vez que diminui o consumo de cimento e consegue-se dar um fim adequado a esses resíduos.

Palavras-chave: Cinza de casca de arroz, Sílica de casca de arroz, Concreto.

\section{ABSTRACT}

The aim of the present work was to analyze and compare the potential of the use of rice husk ash (CCA) and rice husk silica (SCA) in separate mixtures, as a partial replacement material for the cement and also the reduction of the same in different traces of concrete. In order to do so, a reference trait was produced, and from this the substitutions and partial reductions of cement were carried out at different levels. The analyzes allowed to identify which of the two pozzolans studied presented the best performance regarding the axial compressive strength, water absorption, voids index, specific mass and concrete abatement. The study showed that the higher the cement substitution rate for some of the pozzolans, the greater the consistency acquired by the concrete, losing its fluidity. The mixtures presented little difference between them in the voids index, specific mass and water absorption. The mixture that achieved the highest axial compressive strength was S2 (10\% SCA), at 91 days of age, with $25.23 \%$ more resistance than the reference concrete. However, the S6 blend (10\% SCA $+10 \%$ reduction) was most successfully replaced and reduced the amount of cement thus practically maintaining the same characteristics as the reference trace. The study shows that the traces with SCA had superior results to the traces with CCA, also, that it is feasible the partial replacement of the cement by any of the two types of pozolanas studied, increasing the resistance to axial compression of the concrete, obtaining technical benefits and economy because it reduces the consumption of cement and an adequate end to these wastes is achieved.

Keywords: Rice husk ash, Rice husk silica, Concrete. 


\section{INTRODUÇÃO}

O setor da construção civil é um dos que mais consome matéria prima, causando degradação ambiental e não gerando o desenvolvimento sustentável do ambiente construído. Em contrapartida, as vendas de cimento no país atingiram 31 milhões de toneladas no ano de 2017, conforme dados do Sindicato Nacional da Indústria do Cimento. (SNIC, 2018). Essa produção excessiva causa muitos impactos ambientais, principalmente pela liberação de grandes quantidades de dióxido de carbono na atmosfera.

Segundo (SNIC, 2018) o cimento é o produto de uma atividade industrial integrada, obtido a partir da lavra e do beneficiamento de calcário e argila: sua industrialização ocorre mediante moagem, homogeneização e produção da farinha (mistura crua) e posterior processamento físico-químico em clínquer (cimento não pulverizado) e respectiva moagem.

A média mundial de produção de dióxido de carbono $\left(\mathrm{CO}_{2}\right)$ na produção do cimento é de $800 \mathrm{~kg}$ de $\mathrm{CO}_{2}$ por tonelada. No Brasil para cada tonelada de cimento produzida é liberado na atmosfera $600 \mathrm{~kg} \mathrm{de} \mathrm{CO}_{2}$. (SNIC, 2018).

Para garantir a qualidade do meio ambiente, muitas alternativas têm sido criadas, Pádua (2011) enfatiza que as pesquisas voltadas a utilização de resíduos sólidos derivados da agricultura para a produção de argamassas e concretos tornam-se cada vez mais intensas.

Souza (2008) utilizou a cinza da casca do arroz para substituir parte do cimento na confecção de argamassas, esperando que o resultado melhorasse as propriedades físicas e mecânicas. Em seu estudo as argamassas ensaiadas com CCA tiveram o comportamento mecânico superior às argamassas convencionais, ou seja, sem cinza de casca de arroz.

Pensando nesta proposta ambiental, o presente trabalho visa comparar algumas propriedades mecânicas do concreto convencional com as do concreto com substituições parciais de cimento pela cinza de casca de arroz (CCA) e pela sílica de casca de arroz (SCA), e também com a redução parcial do cimento. Observando o comportamento do mesmo quanto às alterações nas propriedades mecânicas como a resistência à compressão axial e o índice de absorção de água de cada traço, para definir qual mistura de concreto terá o melhor desempenho.

\section{A UTILIZAÇÃO DA CINZA DE CASCA DE ARROZ E SÍlICA DE CASCA DE ARROZ}

\subsection{Destino das cinzas de casca de arroz}

De acordo com Santos (2006), a cinza de casca de arroz origina-se da queima da casca de arroz pela produção de energia calorífica empregada, na secagem e parboilização dos grãos, nas beneficiadoras do cereal ou no processo de geração de outras formas de energia, como, em usinas termelétricas, energia elétrica, ou ainda, de processos de calcinação para obtenção de sílica com alto teor de pureza. Segundo Pouey (2006), a quantidade de cinza de casca de arroz gerada com a queima corresponde a $20 \%$ do volume da casca de arroz. A destinação desse resíduo são os aterros sanitários.

Para a diminuição e redução de resíduos destinados a aterros sanitários a Lei Federal 12.305/2010 criou uma política nacional de resíduos onde deve ser seguida uma ordem no que diz respeito à produção dos mesmos, com a finalidade de evitar ao máximo a geração de resíduo, assim, somente será destinado a aterros sanitários o produto que não tem viabilidade econômica, seguindo a ordem hierárquica de não geração, redução, reutilização, reciclagem, tratamento e então disposição final.

Visando a diminuição do resíduo a ser destinado a aterros sanitários surgiram estudos para a utilização da CCA na substituição parcial do cimento na composição de concretos e argamassas, devido a mesma conter um elevado teor de sílica. A sílica é uma combinação de silício e oxigênio na forma $\mathrm{SiO}_{2}$. A cinza da casca de arroz pode conter até $15 \%$ em peso de carbono. Se o aquecimento for promovido com a finalidade de eliminar este carbono residual, pode-se obter aproximadamente $95 \%$ de sílica pura com uma área superficial específica de $10 \mathrm{~m}^{2} / \mathrm{g}$ e partículas com um tamanho em torno de $20 \mu \mathrm{m}$ gerando, assim, um produto com maior valor agregado. (FOLETTO, 2005).

Segundo o Sindicato Nacional da Indústria do Cimento (2018), em média, a produção do cimento mundial gera cerca de $800 \mathrm{Kg}$ de $\mathrm{CO}_{2}$ por tonelada de cimento produzido, logo a pequena parcela de cimento que possa ser substituída por CCA vem ao encontro com as razões ecológicas diminuindo a degradação do meio.

\subsection{A CCA e a SCA como substituição parcial ao cimento}

Segundo Mehta e Monteiro (2008), o concreto tem três motivos que o tornam fundamental na engenharia. O primeiro é o fato de conseguir moldar o concreto em diversas formas. O concreto fresco possui plasticidade e é possível molda-lo em diferentes moldes. Em poucas horas o concreto cura, tornando uma massa rígida e podendo 
retirar as fôrmas. O segundo é a resistência do concreto à água, pois ao contrário de madeiras e aço, por exemplo, o concreto não deteriora em contato com a mesma. O terceiro motivo para o uso de concreto é a facilidade com que é disponível na obra.

Materiais pozolânicos são materiais silicosos ou silico aluminosos que, sozinhos, possuem pouca ou nenhuma atividade aglomerante, mas, quando moídos e na presença da água, reagem com o hidróxido de cálcio para formar compostos com propriedades aglomerantes. As pozolanas podem ser naturais ou artificiais, como, cinzas volantes e argilas calcinadas. Esses materiais têm três classificações: Classe N, pozolanas naturais e artificiais, como certos materiais vulcânicos de caráter petrográfico ácido, terras diatomáceas e argilas calcinadas; Classe C, Cinza volante produzida pela queima de carvão mineral em usinas termoelétricas; Classe E, pozolanas que não se enquadram nas classes anteriores, como a CCA. A norma que rege essas classes é a NBR 12653: 2015 - Materiais pozolânicos - Requisitos.

As adições minerais no concreto são de muita importância e trazem efeitos benéficos devido à redução da porosidade das pastas, isto é, tamponam os poros capilares, distribuem de forma mais homogênea os produtos de hidratação do cimento em relação ao concreto convencional. (MEHTA e MONTEIRO, 2008). A redução da porosidade proporciona uma característica fundamental ao concreto, uma vez que o mesmo adquire característica de menor permeabilidade a fluidos, isto está relacionado com as alterações físicas (fíler) e químicas (pozolanas) do processo de hidratação dos aglomerantes.

Com o elevado consumo de cimento para a produção do concreto, vem sendo estudado o aproveitamento de cinzas de casca de arroz como adições minerais. Essas cinzas possuem propriedades pozolânicas, quando moídas e em presença de umidade, reagem quimicamente com o hidróxido de cálcio gerando compostos mais densos e menos solúveis. (FOLETTO, 2005).

A CCA é uma pozolana que melhora tanto pelo efeito filer quanto pelo efeito pozolânico algumas propriedades de argamassas e concretos. As principais reações químicas são com o hidróxido de cálcio $(\mathrm{CH})$, onde reage quimicamente e precipita na forma de Silicato de Cálcio Hidratado (C-S-H), ou seja, modifica-se de material pouco resistente para um material muito resistente e aderente. Com esta reação, é possível produzir um concreto mais econômico, com baixo calor de hidratação, mais resistentes com baixa porosidade e com resistividade elétrica maior, mais durável frente a vários meios agressivos. (SILVA, 2006).

Através da queima da casca de arroz com temperatura controlada origina-se a sílica de casca de arroz, que possui propriedades físicas e químicas diferentes da CCA. A temperatura de queima é o que determina a reatividade da CCA, pois, através dela será definido o teor de sílica amorfa. Quanto maior a temperatura e o tempo de exposição a ela, menos reativa será a cinza obtida. (WEBER 2001). Para a obtenção da sílica, com a CA, além da simples combustão, a sílica pode ser obtida através do processo de tratamentos físico-químicos da casca de arroz. (POUEY, 2006).

A introdução de CCA para a produção de concretos e argamassas não prejudica propriedades importantes de funcionalidades como: tempos de início e fim de pega, expansibilidade e retração por secagem. (AKASAKI et al., 2005).

No estudo de Dalcin (2016), pode-se concluir que no que tange à reologia no estado fresco foi possível observar que com o aumento da substituição de cimento por cinza de casca de arroz houve piora das características de fluidez e habilidade passante do concreto, porém, conseguiu-se manter as características de concreto auto adensável, isso se deu pelo fato de aumentar a coesão e a viscosidade do concreto no estado fresco quando comparado ao concreto de referência.

Já Tiboni (2007) estudou a confecção de concretos com adição parcial de cinzas de casca de arroz oriundas das termelétricas da indústria de beneficiamento do arroz como adição mineral em concretos duráveis. O resultado obtido com o uso da cinza de casca de arroz para substituir parte do cimento mostrou-se viável, além de ser ecologicamente correto.

Segundo Silva (2004) o uso de CCA em concretos e argamassas mostram aumentos significativos na resistência à compressão axial, para dosagens de 5 e $10 \%$ de CCA. Onde se conseguiu um ganho de resistência de $24 \%$ para concreto e de $28 \%$ para argamassas.

\section{MATERIAIS E MÉTODOS}

O presente trabalho foi desenvolvido através de pesquisas bibliográficas e ensaios laboratoriais. Nas pesquisas bibliográficas foram buscados materiais publicados sobre assuntos que tratavam da sustentabilidade e viabilidade de concretos com substituição do cimento por algum tipo de material pozolânico. Com as atividades em laboratório averiguou-se a melhor dosagem do concreto para as propriedades analisadas quando se utiliza CCA e/ou SCA como substituintes parciais do cimento.

A pesquisa ocorreu no Laboratório de Materiais e Construção Civil da URI - Universidade Regional Integrada, Câmpus de Frederico Westphalen. 


\subsection{Caracterização dos materiais utilizados}

\subsubsection{Caracterização dos agregados}

O agregado graúdo empregado na pesquisa foi a brita basáltica, onde segundo a NBR NM 248:2003 Agregados Determinação da composição granulométrica. Rio de Janeiro 2003, é classificada como brita 1 (um). E o agregado miúdo, uma areia quartzosa bem graduada, encontrando-se na zona utilizável - limite inferior.

\subsubsection{Determinação da massa específica aparente e massa unitária dos agregados}

A massa específica é a densidade do agregado sem nenhum vazio, ou seja, não inclui poros permeáveis e não possui espaços entre os grãos. A massa específica se dá pela divisão da massa pelo volume. Já a massa específica aparente é a relação entre a massa do agregado seco e seu volume, incluindo os poros permeáveis à água (NBR NM 53,2009).

A ABNT NBR NM 53:2009 - Agregado graúdo - Determinação da massa específica, massa específica aparente e absorção de água, recomenda o ensaio para os agregados graúdos e a ABNT NBR NM 52:2009 - Agregado miúdo Determinação da massa específica e massa específica aparente para agregados miúdos.

A determinação da massa unitária de agregado se dá pela razão entre a massa de um agregado lançado em um recipiente e o volume deste recipiente. A massa unitária tem grande importância, pois é por meio dela, que se podem transformar as composições das argamassas e concretos dadas em peso para o volume e vice-versa. A NBR NM 45:2006 Agregados - Determinação da massa unitária e do volume de vazios é quem rege esse ensaio. A Tabela 01 a seguir mostra o resultado da caracterização física dos agregados.

Tabela 01- Características físicas dos agregados

\begin{tabular}{c|c|c}
\hline \multirow{2}{*}{ Características Físicas } & \multicolumn{2}{|c}{ Agregados } \\
\cline { 2 - 3 } & Miúdo & Graúdo \\
\hline Massa específica & $2.59 \mathrm{~g} / \mathrm{cm}^{3}$ & $2.90 \mathrm{~g} / \mathrm{cm}^{3}$ \\
\hline Absorção de água & -- & $0.47 \%$ \\
\hline Massa Unitária & $1.68 \mathrm{~g} / \mathrm{cm}^{3}$ & $1.76 \mathrm{~g} / \mathrm{cm}^{3}$ \\
\hline
\end{tabular}

Fonte: autores.

\subsection{Materiais cimentícios}

O cimento utilizado foi o CP V-ARI da empresa ITAMBÉ, esse cimento Portland tem um grau de moagem elevado que proporciona uma reatividade em baixas idades e uma alta resistência inicial. Escolheu-se este tipo de cimento devido à ausência de adições minerais em sua composição, permitindo uma melhor análise da influência das pozolanas estudadas nas misturas de concreto. As características químicas do material estão disponíveis na página virtual da empresa, e foram adaptadas na Tabela 02.

Tabela 02- Composição química do cimento Porthand CPV-ARI

\begin{tabular}{cc}
\hline COMPOSIÇÃO & MÉDIA \\
\hline $\mathrm{AL2O} 3$ & $4,3 \%$ \\
\hline $\mathrm{SiO} 2$ & $18,96 \%$ \\
\hline $\mathrm{FeO} 3$ & $2,95 \%$ \\
\hline $\mathrm{CaO}$ & $60,76 \%$ \\
\hline $\mathrm{MgO}$ & $3,26 \%$ \\
\hline $\mathrm{SO} 3$ & $3,18 \%$ \\
\hline Perda ao fogo & $3,45 \%$ \\
\hline $\mathrm{CaO}$ Livre & $0.75 \%$ \\
\hline Resíduos insolúveis & $0.72 \%$ \\
\hline Equiv. Alcal. & $0.68 \%$ \\
\hline
\end{tabular}

A CCA que foi utilizada é um resíduo originado da Usina Termelétrica da CAAL (Cooperativa Agroindustrial Alegrete LTDA) onde está projetada para gerar até 3,8 MWh através do consumo médio de $81 \mathrm{t} / \mathrm{dia}$ de casca de arroz. São geradas diariamente cerca de 10 toneladas de cinzas. As cinzas que resultam da combustão da casca de arroz 
apresentam uma composição baseada em $96 \%$ de sílica, podendo esta apresentar diferentes formas cristalinas ou amorfas.

A caracterização química da pozolana foi realizada no laboratório ECONSULTING (Laboratório de Gestão Ambiental e Higiene Ocupacional) no ano de 2015. Os dados são apresentados na Tabela 03.

Tabela 03- Propriedades químicas da cinza de casca de arroz

\begin{tabular}{c|c}
\hline PARÂMETROS & RESULTADOS \\
\hline Matéria orgânica & $9.90 \%$ \\
\hline Cinzas & $89.60 \%$ \\
\hline Umidade & $0.50 \%$ \\
\hline $\mathrm{pH}$ & 8.89 \\
\hline
\end{tabular}

Fonte: autores.

Conforme a classificação do resíduo pela NBR 10004: 2004 - Resíduos sólidos - Classificação, a amostra foi definida como sendo resíduo não inerte Classe IIA.

A Sílica utilizada é proveniente da queima controlada da casca de arroz em sistema de combustão via leito fluidizado pela SILCCA NOBRE, sílica da casca de arroz da cidade de Alegrete RS. A Tabela 04 apresenta os dados obtidos em relação às propriedades físico-química deste material.

Tabela 04- propriedades físico-química da sílica de casca de arroz

\begin{tabular}{c|c} 
PARÂMETROS & RESULTADOS \\
\hline Diâmetro Médio & $<8,0 \mu \mathrm{m}$ \\
\hline $\mathrm{pH}$ & $\leq 10.0$ \\
\hline Perda ao Fogo & $\leq 3.5 \%$ \\
\hline Densidade aparente & $550-600 \mathrm{Kg} / \mathrm{m}^{3}$ \\
\hline Área específica B.E.T. & $20.000 \mathrm{~m}^{2} / \mathrm{Kg}$ \\
\hline Umidade & $<3 \%$ \\
\hline Teor de sílica Amorfa & $>95 \%$ \\
\hline Massa específica & $2,16 \mathrm{~g} / \mathrm{cm}^{3}$ \\
\hline Coloração & Cinza Claro \\
\hline \multicolumn{2}{c}{ Fonte: autores. }
\end{tabular}

A SCA apresenta um elevado teor de sílica onde é classificado como sendo uma pozolana classe E, possui um teor de sílica amorfa maior que $95 \%$, superior ao mínimo de 50\% exigido para ser uma pozolana. Apresenta uma perda ao fogo menor de 3,5\%, inferior ao limite máximo exigido pela norma ABNT NBR 12653: 2015 - Materiais pozolânicos Requisitos.

\subsection{Dosagem do concreto e misturas}

Foi elaborado um traço de concreto referência e tomado como base a sua resistência à compressão axial e absorção de água, para ser comparado com as demais misturas estudadas. Os traços com substituição e redução de cimento por CCA e SCA seguiram as dosagens como demonstra a Tabela 05. 


\section{CBPAT 2020 \\ CONGRESSO BRASILEIRO DE PATOLOGIA DAS CONSTRUÇÕES \\ DE 15 A 17 DE ABRIL | FORTALEZA - CE}

ISBN 978-65-86819-05-2 ASSOCIMC BRASI

Tabela 05- Percentuais de substituição de CCA e SCA

\begin{tabular}{c|c|c|c|c|c}
\hline \multirow{2}{*}{} & \multirow{2}{*}{$\begin{array}{c}\text { Redução de } \\
\text { cimento }\end{array}$} & \multicolumn{2}{|c|}{ Substituição } & \multicolumn{2}{c}{ Substituição } \\
\cline { 3 - 6 } TR/ Traço & CCA & $5 \%$ & $10 \%$ & $5 \%$ & $10 \%$ \\
\cline { 2 - 6 } Referência & $5 \%$ & $\mathrm{C} 1$ & $\mathrm{C} 2$ & $\mathrm{~S} 1$ & $\mathrm{~S} 2$ \\
\cline { 2 - 6 } & $10 \%$ & $\mathrm{C} 3$ & $\mathrm{C} 4$ & $\mathrm{~S} 3$ & $\mathrm{~S} 4$ \\
\cline { 2 - 7 } & & $\mathrm{C} 5$ & $\mathrm{C} 6$ & $\mathrm{~S} 5$ & $\mathrm{~S} 6$ \\
\hline
\end{tabular}

Fonte: autores.

Para a produção das diferentes misturas de concreto manteve-se a mesma relação água/materiais cimentícios do concreto referência, essa relação foi definida através do ensaio de abatimento quando o mesmo atingiu $87 \mathrm{~mm}$. Considerando que o tempo de mistura influencia diretamente no abatimento do concreto com substituição parcial de CCA ou SCA, registrou-se o tempo de mistura em betoneira do traço referência e manteve-se o mesmo tempo de mistura para os demais traços em análise.

A dosagem do concreto referência foi de modo empírico na relação 1:5, onde para cada uma unidade em massa de cimento utilizou-se 5 unidades de agregados.

Para que o concreto tenha uma boa trabalhabilidade e consiga ser lançado e adensado adequadamente sem a segregação do agregado graúdo é preciso um teor ideal de argamassa. O teor de argamassa utilizado foi de 55\%, ou seja, 55\% da massa total da mistura (cimento, agregado miúdo e graúdo).

Assim, definiu-se o traço referência, em massa de 1: 2,3: 2,7; 0,49 (cimento: agregado miúdo: agregado graúdo: relação água/materiais cimentícios). A composição dos demais traços está representada na Tabela 06.

Tabela 06- Composição dos traços a serem analisados

\begin{tabular}{|c|c|c|}
\hline \multicolumn{2}{|c|}{$\begin{array}{l}\text { Nomenclatura } \\
\text { de cada traço }\end{array}$} & $\begin{array}{c}\text { Traço unitário } \\
\text { Cimento: Pozolana: Areia: Brita: Água }\end{array}$ \\
\hline \multicolumn{2}{|c|}{ T.R } & 1: $0: 2,3: 2,7: 0,49$ \\
\hline \multirow{6}{*}{ CCA } & $\mathrm{C1}$ & $0,95: 0,05: 2,3: 2,7: 0,49$ \\
\hline & $\mathrm{C} 2$ & $0,90: 0,10: 2,3: 2,7: 0,49$ \\
\hline & $\mathrm{C3}$ & $0,90: 0,05: 2,3: 2,7: 0,49$ \\
\hline & $\mathrm{C4}$ & $0,85: 0,10: 2,3: 2,7: 0,49$ \\
\hline & C5 & $0,85: 0,05: 2,3: 2,7: 0,49$ \\
\hline & C6 & $0,80: 0,10: 2,3: 2,7: 0,49$ \\
\hline \multirow{6}{*}{ SCA } & S1 & $0,95: 0,05: 2,3: 2,7: 0,49$ \\
\hline & S2 & $0,90: 0,10: 2,3: 2,7: 0,49$ \\
\hline & S3 & $0,90: 0,05: 2,3: 2,7: 0,49$ \\
\hline & S4 & $0,85: 0,10: 2,3: 2,7: 0,49$ \\
\hline & S5 & $0,85: 0,05: 2,3: 2,7: 0,49$ \\
\hline & S6 & $0,80: 0,10: 2,3: 2,7: 0,49$ \\
\hline
\end{tabular}

Fonte: autores. 


\section{RESULTADOS E DISCUSSÕES}

\subsection{Ensaio de Consistência do concreto}

O Figura 01 a seguir mostra o resultado do ensaio de consistência pelo abatimento de tronco de cone realizados em todos os traços.

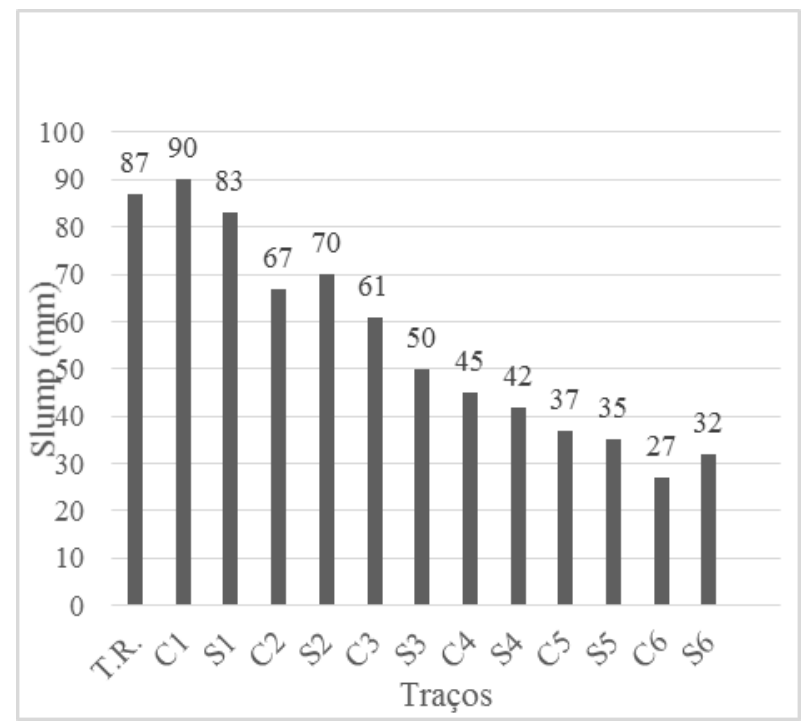

Figura 01 - Ensaio de consistência do concreto pelo abatimento de tronco de cone

A partir dos ensaios de abatimento do tronco de cone verifica-se que tanto com a substituição das pozolanas quanto com a redução do cimento nos traços em análise fez com que o concreto perdesse fluidez e ganhasse viscosidade, os traços apresentaram-se com aumento da consistência, assim diminuindo os valores de ensaio. $\mathrm{O}$ traço $\mathrm{C} 1$ foi o que teve o maior abatimento, com um ganho de 3,45\% no abatimento quando comparado com o T.R. Já o traço C6 foi o que apresentou menos abatimento quando comparado com o T.R. teve uma perda de 68,96 \% em seu abatimento. Dalcin (2016), já tinha previsto em estudo que quanto maior a substituição de cimento por alguma das pozolanas os traços tornam-se mais denso, devido as pozolanas absorverem mais água que o cimento e também pela redução da porção do mesmo.

No estudo de Cordeiro et al (2009) onde analisou a influência da CCA em diferentes proporções em concretos convencionais e em concretos de alta resistência obteve uma redução dos valores de ensaio de abatimento em todos os traços em análise. Cordeiro et al (2009) atribui essa redução do abatimento devido a CCA ter elevada área superficial, necessitando assim de mais água para envolver a partícula.

As Figuras 02 e 03 mostram a diferença de abatimento de tronco de cone entre o T.R. e o C6, traço que obteve-se o menor valor de ensaio. 

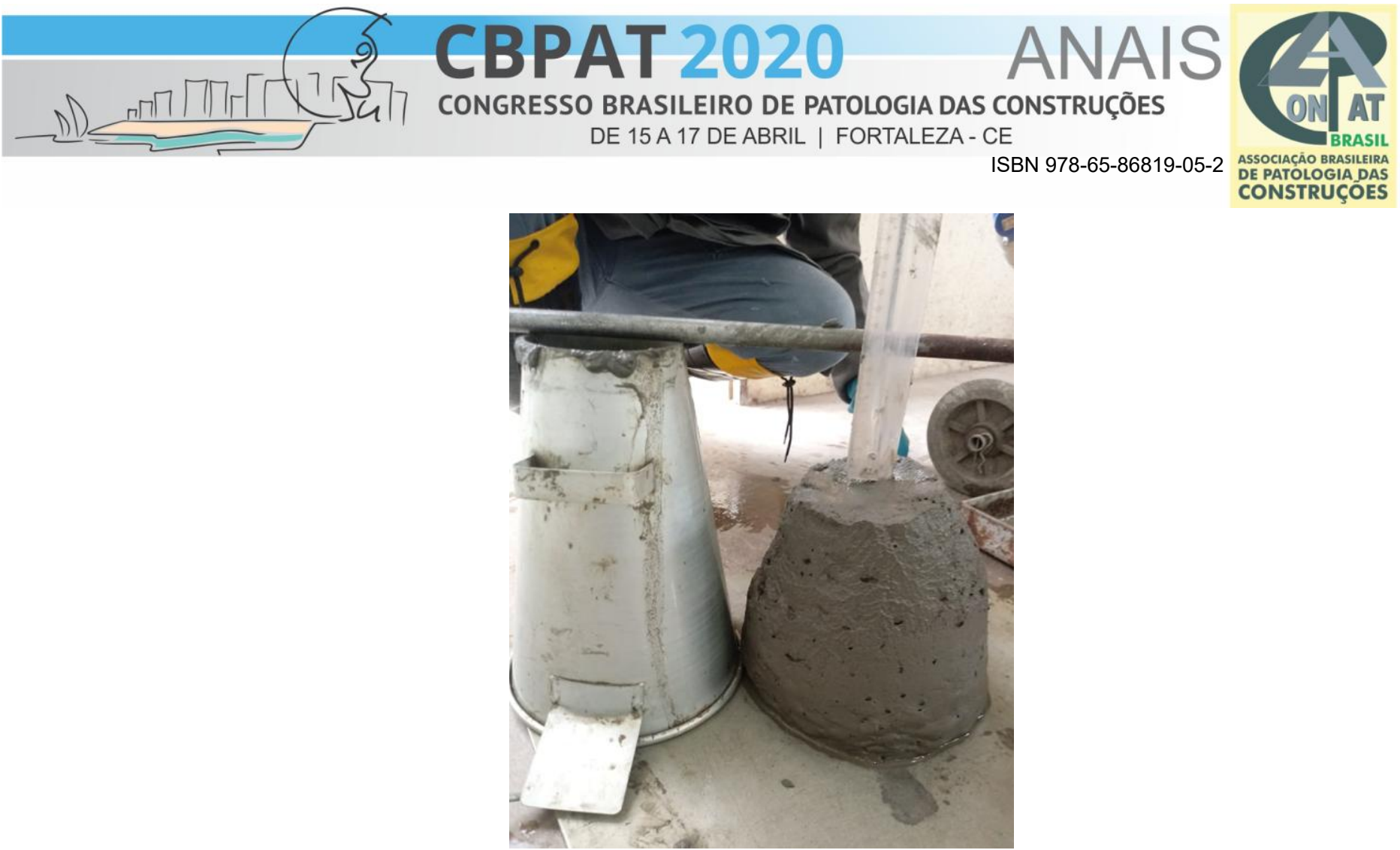

Figura 02- Ensaio de consistência pelo abatimento do tronco de cone do T.R.

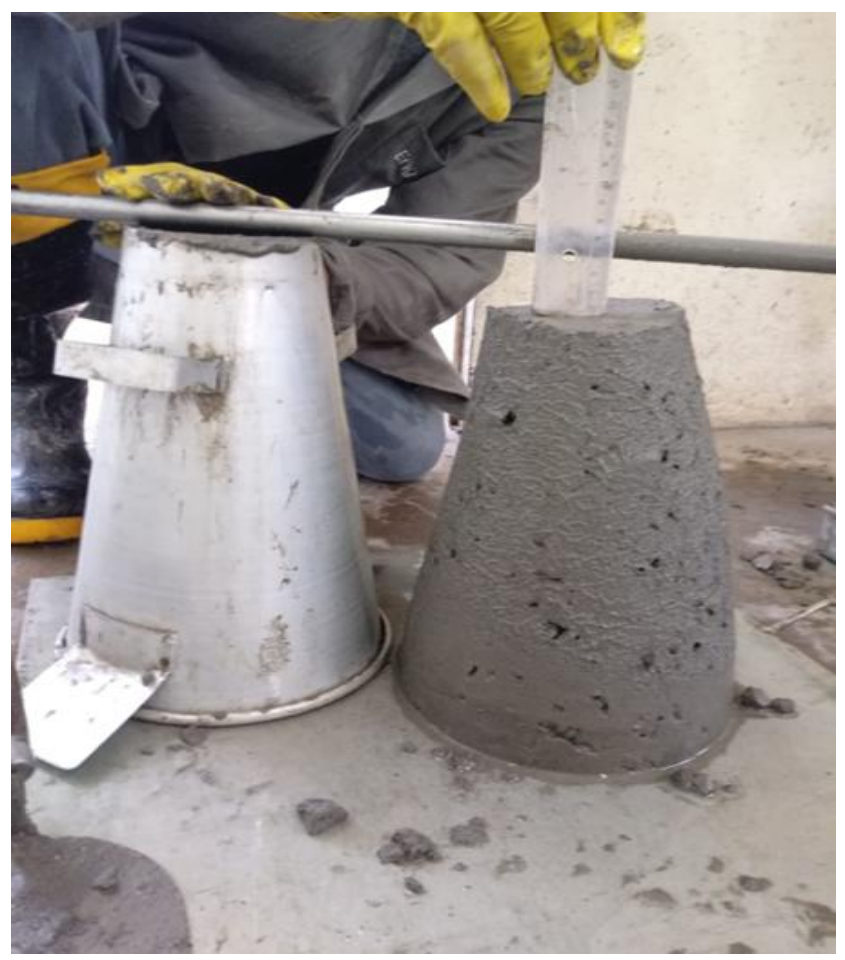

Figura 03- Ensaio de consistência pelo abatimento do tronco de cone do C6

\subsection{Ensaio de absorção de água, índice de vazios e massa específica}

Foram feitos os ensaios de absorção de água, índice de vazios e massa específica como recomenda a NBR 9778:2009 Argamassa e concreto endurecidos - Determinação da absorção de água por imersão - Índice de vazios e massa específica. A Figura 04 mostra os valores obtidos com o ensaio de absorção de água. 


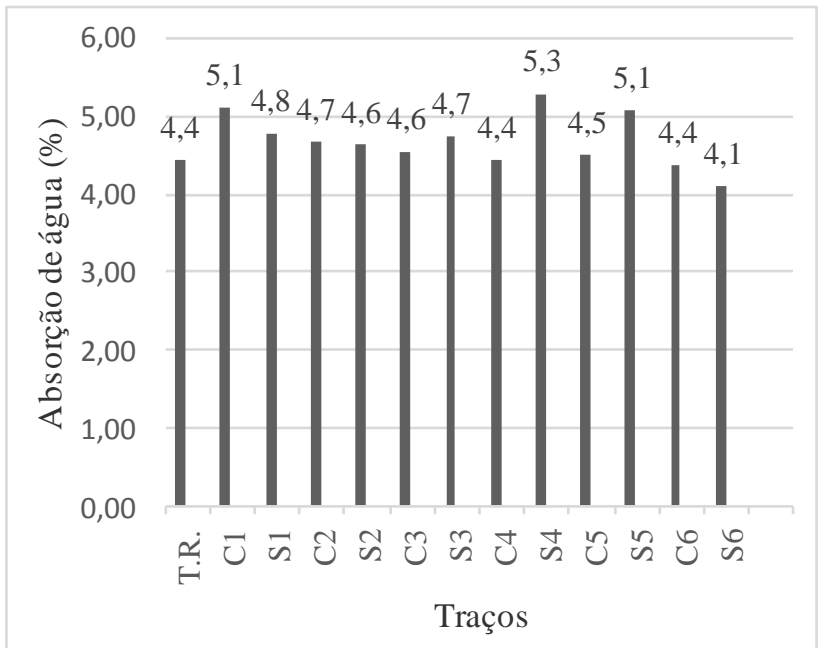

Figura 04- Ensaio de Absorção de água

A partir do ensaio de absorção de água conseguiu-se analisar que com exceção dos traços C4 e S6, os demais traços tiveram um aumento no teor de absorção de água. $\mathrm{O}$ traço $\mathrm{C} 4$ manteve-se no mesmo teor de absorção de água do T.R. e o S6 mostrou-se com uma redução na absorção de água. O traço S4 foi o que mais absorveu água comparado com o T.R. teve um aumento de 19,37 \% na absorção de água. O traço S6 foi o que menos absorveu água comparado com o T.R. teve absorção de água $7,43 \%$ a menos que o T.R. Na média geral os traços tiveram um aumento de absorção de água de $5,74 \%$.

O fato de ocorrer um aumento na absorção de água segundo Bezerra et al (2011), provavelmente, se deve a grande quantidade de agregado miúdo na constituição dos traços, favorecendo um índice maior de vazios, já que também teve redução na porção de cimento.

Nascimento (2002), analisando concretos com substituição de $5 \%$ e $10 \%$ de CCA, curados em câmara úmida por 91 dias, constatou que, os valores de absorção são ligeiramente superiores aos valores dos concretos de referência.

No estudo de Oldra (2015), onde estudou traços com 3, 5 e $10 \%$ de substituição de cimento por CCA e avaliou o índice de vazios, massa específica e absorção de água dos traços aos 28,56 e 90 dias de idade, pode concluir que aos 28 dias de idade a absorção de água do traço com $10 \%$ de substituição de cimento por CCA era maior que ao seu traço referência. Já aos 90 dias de idade todas as suas amostras encontravam-se com absorção de água menor ao seu traço referência. Segundo Oldra (2015) isso se justifica pelo fato da pozolana levar mais tempo para reagir quimicamente e ao final de 90 dias adquirir uma mistura mais densa tornando-a menos porosa.

Os ensaios de índice de vazios estão representados na Figura 05.

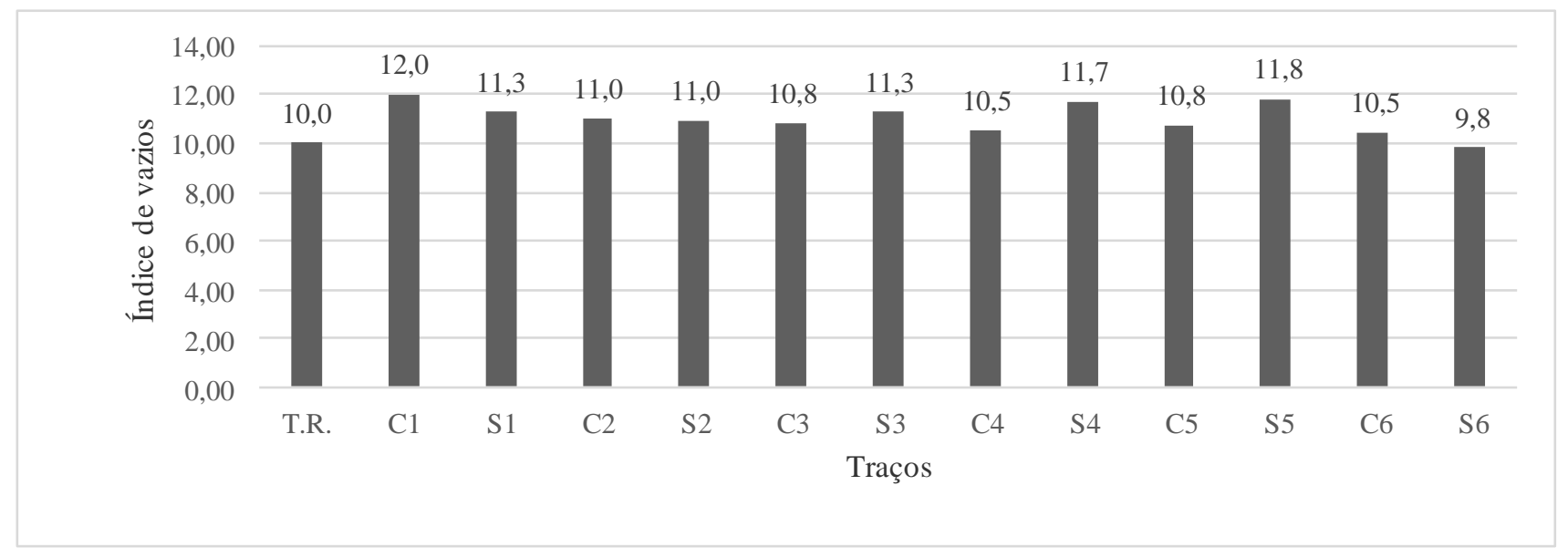

Figura 05- Índice de vazios 
Analisando os ensaios de índice de vazios de cada traço pode-se observar que o traço S6 teve uma redução de vazios comparado com o T.R., porém, os demais traços mostram-se com um teor maior de vazios que o T.R. O S6 teve uma redução de $1,80 \%$ de vazios quando comparado com o T.R., O traço C1 foi o que mais apresentou vazios, teve um aumento de 20,16\% de vazios quando comparado com o T.R. Em média obteve-se um aumento nos vazios de $10,32 \%$ comparado com o T.R.

Como citado anteriormente, para Bezerra et al (2011) a redução na porção de cimento e consequentemente a maior quantidade de agregado miúdo na constituição dos traços favorecem um maior índice de vazios. Oldra (2015), em estudo de concretos com substituição parcial de cimento por CCA mostra que aos 28 dias de idade a sua mistura com 10 $\%$ de substituição de cimento por CCA apresentou índices de vazios maiores que o traço referência, já aos 90 dias todos os seus traços com substituição tiveram menor índices de vazios que o traço referência, devido a CCA ter reação química diferente a do cimento. O autor ainda afirma que o tempo de cura do concreto influencia no índice de vazios e na absorção de água do mesmo, quanto maior o tempo de cura, menor o índice de vazios e menor a absorção de água. Os resultados dos ensaios de massa específicas estão representados na Figura 06 a seguir.

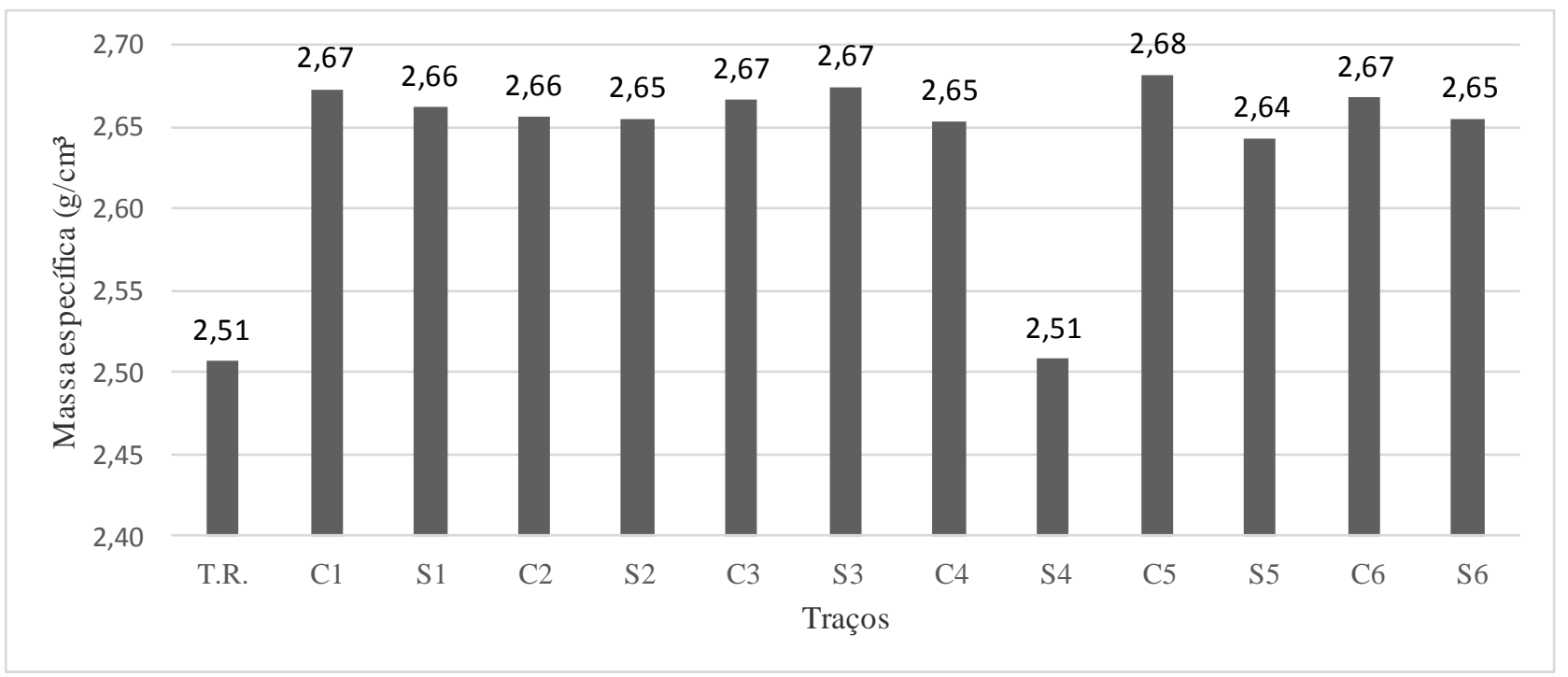

Figura 06- Massa específica

Comparando os ensaios de massa específica de cada traço pode-se observar que apenas o traço S4 manteve-se com a mesma característica que o T.R., ou seja, $2,51 \mathrm{~g} / \mathrm{cm}^{3}$, os demais tiveram um aumento médio de 5,97\% nas suas massas específicas quando comparadas com o T.R. Os valores obtidos podem ser justificados pelo fato das adições minerais agirem na mistura tornando-a mais densa. (BEZERRA et al., 2011).

Entre os dois primeiros ensaios índice de vazios e massa específica pode-se perceber que não houve uma variação significativa entre as duas pozolanas estudadas.

\subsection{Resistência à compressão axial}

Serão apresentados na Figura 07 a evolução da resistência a compressão axial do concreto obtida com a média de três corpos-de-prova para as idades de 7, 28 e 91 dias, que foram ensaiados segundo recomendações da NBR 5739: 2007 Concreto - Ensaio de compressão de corpos-de-prova. 


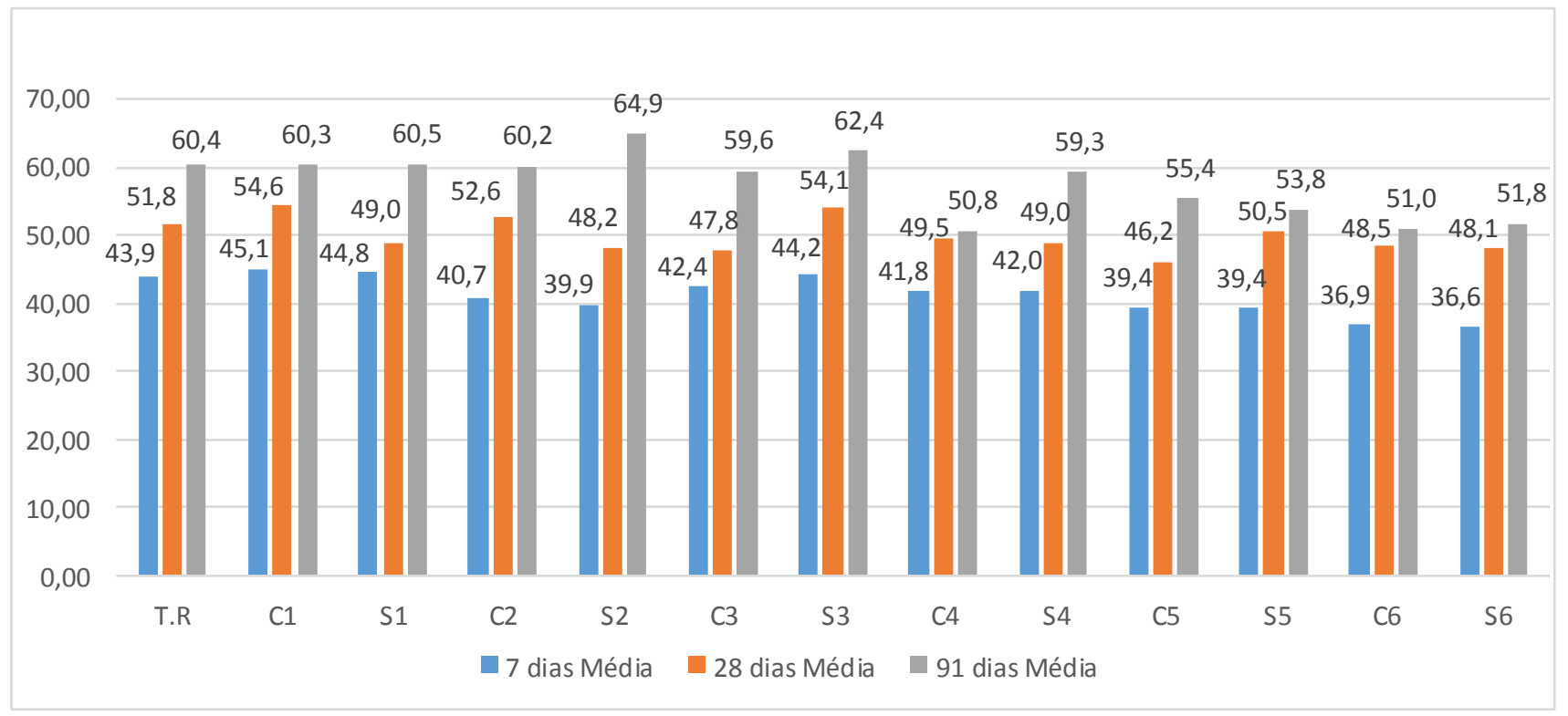

Figura 07- Média da compressão axial dos traços aos 7, 28 e 91 dias

Tomando como base a resistência à compressão axial aos 28 dias de idade do T.R. pode-se definir que:

- Os traços C4 e C6 nas idades de 91 dias não atingiram a resistência do T.R. aos 28 dias.

- Os demais traços aos 91 dias de idade apresentaram resistência maior ou igual a do T.R. aos 28 dias de idade.

Na Figura 08 estão apresentados os resultados de resistência à compressão axial de todas as misturas estudadas em porcentagem tomando como base a resistência do T.R.

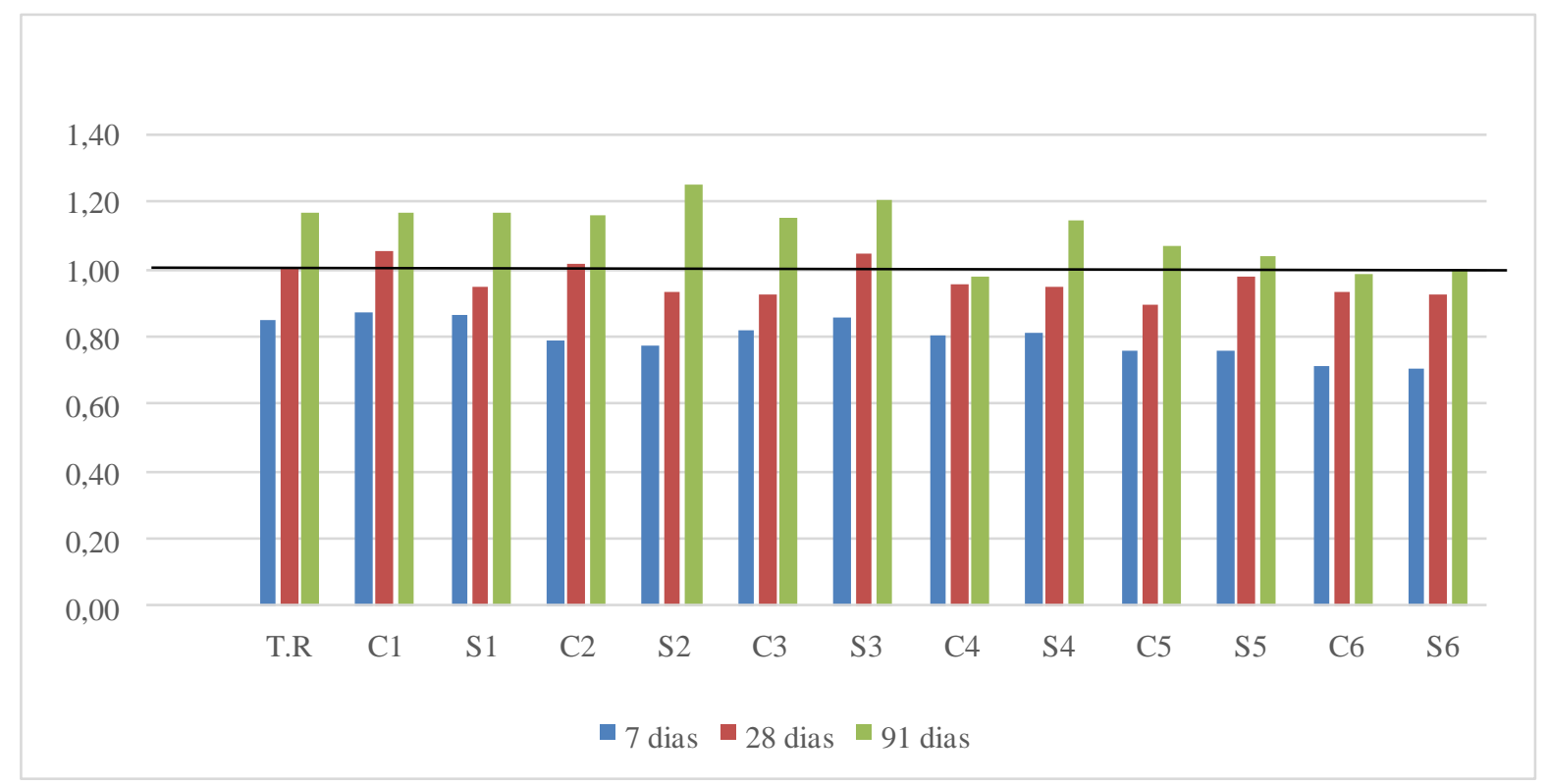

Figura 08- Porcentagem da resistência à compressão axial tomando como referência a resistência aos 28 dias do T.R.

Ao analisar-se todas as resistências à compressão axial dos traços percebemos que a resistência não é proporcional ao teor de substituição de pozolanas, o que vem de encontro com o estudo de Ludwig (2014) que em seu estudo substituiu cimento por CCA em teores de 3, 5 e $7 \%$, e comparou com um traço referência. Constatou que os traços de 3 e $7 \%$ têm maior resistência à compressão axial que o traço de 5\% de substituição de cimento por CCA.

Para Bezerra et al (2011), o aumento da resistência em idades mais avançadas pode ser atribuído, à reação da CCA com o hidróxido de cálcio formando o C-S-H, material resistente e estável, que favorece o aumento da resistência (reação pozolânica). Para Malhotra e Metha (1996), o bom desempenho de traços com CCA é explicado pelo fato de haver 
preenchimento dos vazios da argamassa, denominado efeito filler, aumentando o empacotamento das partículas e diminuindo, assim, os vazios, favorecendo positivamente a resistência a compressão simples.

Aos 91 dias de idade os traços S2 e S3 mostraram-se com as maiores resistências, logo nesses traços apresentou-se a reação pozolânica devido conter a sílica de casca de arroz. Essa reação tende a se desenvolver em idades superiores de 28 dias. (SILVA et al., 2009).

\section{CONCLUSÃ̃o}

O objetivo do devido trabalho foi encontrar uma alternativa para o uso do resíduo proveniente da queima de casca de arroz pelas usinas de beneficiamento do grão. O estudo mostrou que quanto maior for o índice de substituição e redução de cimento por alguma das pozolanas maior será a consistência do concreto, perdendo a fluidez e a habilidade passante do concreto, devido as pozolanas absorverem mais água. Sugere-se que utilize aditivo plastificante junto ao concreto para que diminua a viscosidade das misturas.

O ensaio de massa específica realizado em cada traço mostrou que o S4 (substituição de $10 \%$ de cimento e redução de $5 \%$ ) manteve-se com a mesma característica que o T.R., ou seja, 2,51 g/ $\mathrm{cm}^{3}$, os demais tiveram um aumento médio de $5,97 \%$ nas suas massas específicas quando comparadas com o T.R. Entre os ensaios de índice de vazios e massa específica percebe-se que não obteve-se variação significativa entre os traços.

Quanto aos ensaios de resistência à compressão axial os traços com sílica de casca de arroz mostraram-se com resultados ligeiramente superiores aos traços com cinza de casca de arroz. Com exceção dos traços C4 e C6 os demais mostraram-se viáveis por adquirirem maior resistência que o traço referência aos 28 dias de idade. O traço S2 (10\% de substituição de cimento por sílica de casca de arroz) teve o maior ganho de resistência chegando a 64,87 MPa aos 91 dias. O que corresponde a 25,23\% de resistência a mais do T.R. aos 28 dias, porém, com o traço S6 (aos 91 dias) pôdese substituir um teor de pozolana de $10 \%$ e reduzir $10 \%$ de cimento, tendo a mesma resistência do T.R. aos 28 dias de idade, possibilitando assim, substituir uma maior porcentagem de pozolana e consequentemente reduzir uma proporção maior de cimento.

Logo, as substituições de CCA e de SCA trazem benefícios ambientais, técnicos e financeiros, sendo que substituindo CCA ou SCA parcialmente na composição do concreto consegue-se dar um destino adequado ao resíduo, o concreto tem um ganho em algumas propriedades mecânicas e torna-se uma alternativa econômica por possibilitar a redução do consumo de cimento.

\section{REFERÊNCIAS}

ASSOCIAÇÃO BRASILEIRA DE NORMAS TÉCNICAS. NBR 5738: Concreto - Procedimento para moldagem e cura de corpos-de-prova. Rio de Janeiro 2016.

NBR 10004: Resíduos sólidos - Classificação. Rio de Janeiro. 2004.

NBR 5739: Concreto - Ensaio de compressão de corpos-de-prova. Rio de Janeiro. 2007.

. NBR 12653: Materiais pozolânicos - Requisitos. Rio de Janeiro 2015.

. NBR 9778: Argamassa e concreto endurecidos - Determinação da absorção de água por imersão. Rio de Janeiro 2009.

. NBR NM 45: Agregados - Determinação da massa unitária e do volume de vazios. Rio de Janeiro 2006. janeiro 2009.

NBR NM 52:2009 - Agregado miúdo - Determinação da massa específica e massa específica aparente. Rio de janeiro 2009.

NBR NM 53: Agregado graúdo - Determinação da massa específica, massa específica aparente e absorção de água. Rio de Janeiro 2009.

NBR NM 67: 1996. Concreto - Determinação da consistência pelo abatimento do tronco de cone. Rio de Janeiro 1996.

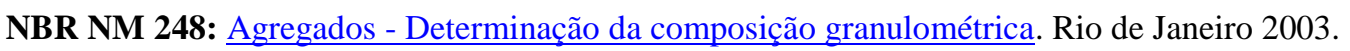


AKASAKI, J. L.; SILVA, E. J.; TASHIMA, M. M.; BARBOSA, M. B. Influência da adição de cinza de casca de arroz nos tempos de pega e retração por secagem. In: Simpósio Ibero-Americano, 2005, Coimbra - Portugal. Anais... Portugal: SIABE 05, 2005.

BEZERRA, I. M. T.; SOUZA, J.; CARVALHO, J. B. Q.; NEVES, G. A. Aplicação da cinza da casca do arroz em argamassas de assentamento. Revista Brasileira de Engenharia Agrícola e Ambiental v.15, n.6, p.639-645, 2011, Campina Grande, PB, UAEA/UFCG 03,2011.

BRASIL. Lei $\mathbf{n}^{\circ}$ 12.305, de 2 de agosto de 2010. Institui a Política Nacional de Resíduos Sólidos; altera a Lei $\mathrm{n}^{\circ} 9.605$, de 12 de fevereiro de 1998; e dá outras providências. Disponível em < http://www.planalto.gov.br/ccivil_03/_ato2007-

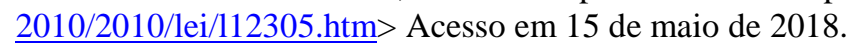

CORDEIRO, G. C.; FILHO, R. D. T.; FAIRBAIRN, M.R. Influência da substituição parcial de cimento por cinza ultrafina da casca de arroz com elevado teor de carbono nas propriedades do concreto. Monografia (Programa de pós-graduação em Engenharia Civil). Universidade Estadual do Norte Fluminense Darcy Ribeiro, Rio de Janeiro. 2009.

DALCIN, Jarbas Bressa. Avaliação do uso da sílica de casca de arroz obtida através da queima controlada como substituição parcial ao Cimento Portland na produção de concretos autoadensáveis. Dissertação (mestrado). Alegrete, 2016. Universidade Federal do Pampa- UNIPAMPA, Programa de pós-Graduação em Engenharia. 2016.

FOLETTO, HOFFMANN, SCOPEL, LIMA, JAHN; Aplicabilidade das cinzas da casca de arroz. Departamento de Engenharia Química, UFSM - RS. Quim. Nova, V 28 Nº 6, 2005.

ITAMBÉ. Cimento para toda a obra. Disponível em $<$ http://www.cimentoitambe.com.br/relatorios-deensaio/?pro=371>. Acesso em 01 de maio de 2018.

LUDWING, Douglas Giongo. Concreto com adição de cinza de casca de arroz. Monografia (Centro de Ciências Exatas e Tecnológicas) - Centro Universitário Univates, Lajeado, 2014.

Malhotra, V. M.; MEHTA, P. K. Pozzolanic and cementitious materials. 1.ed. Amsterdam: Advances in Concrete Technology, 1996. 191p.

MEHTA, P. K.; MONTEIRO, P. J. M. Concreto: Microestrutura, Propriedades e Materiais. São Paulo: PINI, 2008.

NASCIMENTO, W. N.; et al. Adição de cinza de csca de arroz CCA no concreto, sob o aspecto da durabilidade. In: $44^{\circ}$ CONGRESSO BRASILEIRO DE CONCRETO. Anais. São Paulo: IBRACON, 2002.

OLDRA, Gean. Avaliação da durabilidade de concretos fabricados com baixos terrores de sílica de casca de arroz imersos em solução de sulfato de magnésio. Monografia (graduação em Engenharia Civil) - Universidade Federal do Pampa, Alegrete.2015.

PÁDUA, P. G. L. Argamassas para concretos estruturais confeccionados com cinza de bagaço de cana-de-açúcar in Natura. In: Congresso Brasileiro do Concreto, 53, 2011, Florianópolis: IBRACON, 2011.

POUEY, M. T. F. Beneficiamento da cinza de casca de arroz residual com vistas à produção de cimento composto e/ou pozolânico. Tese (Doutorado). Porto Alegre, 2006. Universidade Federal do Rio Grande do Sul, Escola de Engenharia, Programa de Pós-Graduação em Engenharia Civil. 2006.

SANTOS, S. Produção e Avaliação do uso de pozolana com baixo teor de carbono obtida da cinza de casca de arroz residual para concreto de alto desempenho. Tese (Doutorado). Universidade Federal de Santa Catarina, Florianópolis, 2006.

SILVA, C. A. R. Aplicação do Conceito de Maturidade em concretos com adição da cinza de casca de arroz. 2004. 115p. Dissertação (Mestrado em engenharia Civil) - Universidade Estadual Paulista "Júlio de Mesquita Filho", Ilha solteira, 2004. 
SILVA, E. J.; AKASAKI, J. L.; DASNOY, J. Influência das variáveis envolvidas no plantio de arroz nas características da cinza de casca de arroz. Ambiente Construído, v.9, p.67-82, 2009.

SILVA, E.J, RICCI E.C, AKASAKI J.L, TASHIMA.MT. Análise da variação da retração por secagem em argamassas com a adição da cinza de casca de arroz. Anais do VI Simpósio EPUSP sobre Estruturas de Concreto, Abril / 2006.

SINDICATO NACIONAL DA INDÚSTRIA DO CIMENTO (Org.). Produção Regional 2017. Disponível em: <http://snic.org.br/assets/pdf/numeros/1520358608.pdf>. Acesso em: 15 mar. de 2018.

SOUZA, J. Estudo da durabilidade de argamassas utilizando cinzas e casca de arroz no traço. Tese de doutorado. Universidade Federal de Campina Grande - UFCG. Campina Grande - PB, 2008.

TIBONI, R. A Utilização da Cinza da Casca de Arroz de Termoelétrica como Componente do Aglomerante de Compósitos à Base de Cimento Portland. Dissertação de mestrado. Universidade de Sao Paulo. Sao Carlos - SP, 2007.

WEBER, Silvana Leonita. Metodologia para Obtenção de Sílica de Elevada Reatividade para Uso em concreto de Alto Desempenho a Partir do Processamento de Cinza de Casca de Arroz. Florianópolis, 2001. 98p. Dissertação (Mestrado em Engenharia Civil). Curso de Pós-Graduação em Engenharia Civil, Universidade Federal de Santa Catarina. 2001. 